\title{
A Unifled Smoking-Automated Colorimetric System for the Analysis of the Gas Phase of Cigarette Smoke and its Application to the Determination of Hydrogen Sulfide*
}

\author{
by P. F. Collins and J. F. Williams
}

Research Department, Liggett \& Myers Tobacco Company, Durbam, N.C., U.S.A.

\section{INTRODUCTION}

The determination of a number of components of the gas phase of cigarette smoke can be readily accomplished by application of colorimetric procedures. While many of these procedures as described for smoke analysis have been simplified through use of automatic chemical analyzers, considerable manual effort is usually still required to collect the gas phase sample and render it into a suitable form for presentation to the analyzer. For example, the component of interest may be collected on a solid trapping material which requires preparation of the trap and then after collection of the sample, removal of the component from the trapping material to a solution. In addition to the effort required in these manual operations, the effect of aging must be taken into consideration as many of the compounds in the gas phase which are of interest are sufficiently reactive so that their concentrations may decrease on standing, even when collected on a trapping material.

The present work was undertaken to explore the feasibility of coupling an automated colorimetric analyzer, the AutoAnalyzer I, directly to a simple smoking machine with particular application of the system to the determination of gas phase hydrogen sulfide. As is well known,

\footnotetext{
* Presented, in part, at the 32nd Tobacco Chemists' Research Conference, Montreal, Canada, October 1978.

Received: 13th December 1978 - accepted: 22nd June 1979.
}

hydrogen sulfide is a highly reactive compound and the accurate determination of small amounts by wet chemical methods requires careful attention to prevent losses through air oxidation or undesired complexation by metallic impurities in the reagents. Furthermore, it has been reported that with gas phase of cigarette smoke, hydrogen sulfide concentrations rapidly decrease on aging $(69 \%$ loss in one minute) and that metal surfaces may both irreversibly absorb and catalyze reaction with other gas phase components (2). Thus, a combined smoking and analysis system in which the time between smoke generation and absorption of soluble components of the gas phase is reduced to only a few seconds and in which contact with metallic surfaces is minimized might be especially useful for the determination of hydrogen sulfide. Such a system has been developed and utilized for the puff-by-puff analysis of the hydrogen sulfide delivery of various U.S. commercial brand cigarettes, as is described in the following sections.

\section{MATERIALS AND METHODS}

\section{Apparatus}

The combined smoking and automated colorimetric system is schematically illustrated in Figure 1. The interfacing of the smoker to the analyzer is based on the ability of a suitable absorbing solution to efficiently scrub

Figure 1. Smoking system and AutoAnalyzer manifold for $\mathrm{H}_{2} \mathrm{~S}$ In gas phase of clgarette smoke.

HO, D1 and D2 are standard AutoAnalyzer I connectors, SMC and DMC are 14 and 28-turn AutoAnalyzer mixing coils and CFO represents the critical flow orifice.

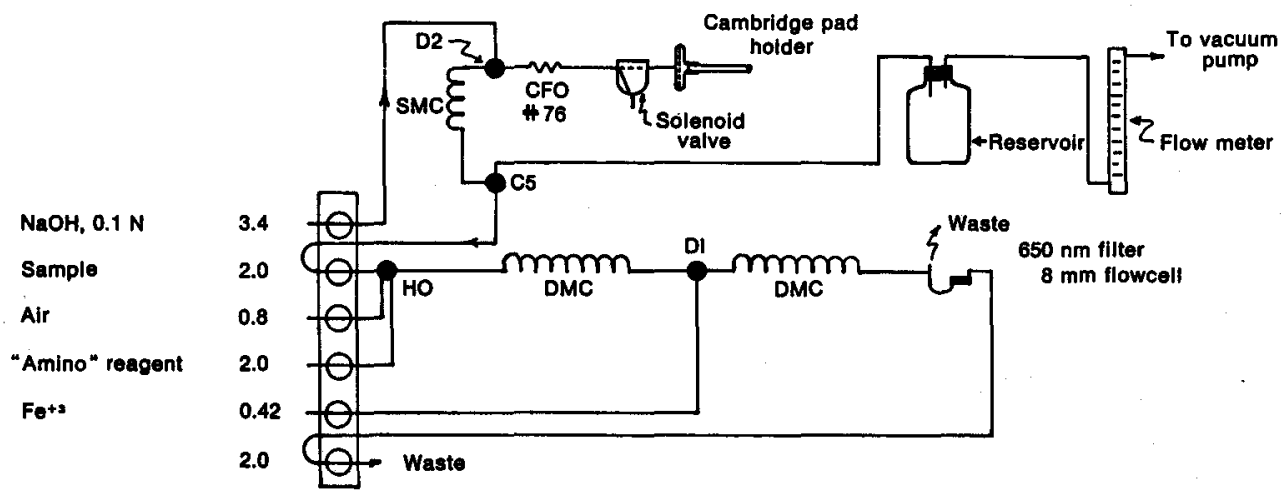


a component from a gas stream when the liquid and gas are passed concurrently through a glass coil; this principle has been previously utilized in automated systems for air monitoring (7).

The smoking system consists of a Cambridge filter assembly connected with Tygon tubing to a solenoid valve (Skinner), a No. 76 critical flow orifice, the absorbing coil, a liquid waste reservoir, a flowmeter (0.2-2.0 liters per $\mathrm{min}$ ) and a rotary vacuum pump (Gast). The solenoid valve is operated by a 60-second cycle timer adjusted so that the valve is actuated for 2 seconds each minute. A continuous gas flow is maintained through the absorbing coil with air being drawn in through the solenoid when the cigarette is not being puffed. The vacuum is adjusted so that a standard $35 \mathrm{ml}$ puff is obtained as measured at the cigarette end of the Cambridge filter assembly with a soap film manometer. The puff shape obtained with this smoker is essentially rectangular. The connectors, D2 and $\mathrm{C} 5$, and the 14-turn glass coil, $2.4 \mathrm{~mm}$ inside diameter, are standard AutoAnalyzer I (Technicon Corp.) components.

The analyzer section is an AutoAnalyzer I, consisting of a Pump I, a colorimeter-recorder unit with $650 \mathrm{~nm}$ filters and an $8 \mathrm{~mm}$ flowcell, and various standard tubes, coils and connectors. The system as shown is designed primarily for the analysis of cigarettes which have a relatively low gas phase delivery of $\mathrm{H}_{2} \mathrm{~S}$, such as those with ventilated filters. This system was used for most of the work reported herein. However, if the analysis of non-filter or non-ventilated filter cigarettes is of primary interest, then it is advisable to modify the manifold to dilute the solution before it enters the colorimeter, thereby assuring that the response for the higher, latter puffs of a cigarette are

Figure 2. Reservoir for standard gas mixture used in callbration.

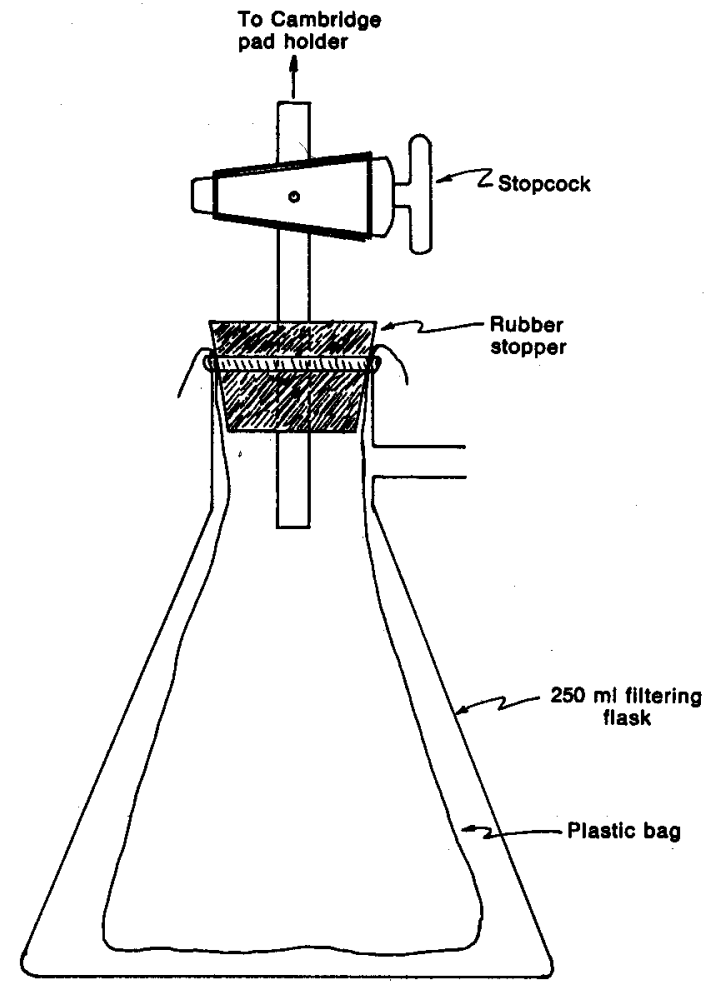

within the linear portion of the calibration curve. This may be done by adding $2.0 \mathrm{ml} / \mathrm{min}$ each of water and "amino" reagent to the stream after the second double mixing coil, through an Ho fitting, and then following this with another 28 -turn mixing coil prior to introducing the stream into the colorimeter.

For the preparation of standard gas mixtures for calibration, a $200 \mathrm{ml}$ glass syringe, a $25 \mu \mathrm{l}$ gas-tight syringe and cylinders of $\mathrm{N}_{2}$ and $\mathrm{H}_{2} \mathrm{~S}$ are required. In this work, research grade nitrogen $(99.99 \%)$ and hydrogen sulfide (Matheson C. P., 99.5\% min, liquid phase) were used. The gas mixture is prepared in the large syringe and then dispensed into a polyethylene bag arranged as shown in Figure 2. The stopcock is connected with Tygon tubing to the Cambridge pad assembly for calibration.

\section{Reagents}

1. $\mathrm{NaOH}, 0.1 \mathrm{~N}$. Dissolve and dilute $8.0 \mathrm{~g}$ of reagent grade $\mathrm{NaOH}$ to $2000 \mathrm{ml}$ with deionized water.

2. "Amino" reagent. Dissolve $0.50 \mathrm{~g}$ of $\mathrm{N}, \mathrm{N}$-dimethyl-pphenylene diamine sulfate (Eastman White Label No. 1333 ) in $350 \mathrm{ml}$ of distilled water. Add $100 \mathrm{ml}$ of conc. $\mathrm{H}_{2} \mathrm{SO}_{4}$, cool and dilute to $500 \mathrm{ml}$ with distilled water. For use on the AutoAnalyzer, dilute $100 \mathrm{ml}$ of this stock solution to $500 \mathrm{ml}$ with distilled water.

3. $\mathrm{Fe}^{+3}$ solution. Dissolve $25 \mathrm{~g}$ of reagent grade ferric ammonium sulfate, $\mathrm{FeNH}_{4}\left(\mathrm{SO}_{4}\right)_{2} \cdot 12 \mathrm{H}_{2} \mathrm{O}$, in $5 \mathrm{ml}$ of $\mathrm{H}_{2} \mathrm{SO}_{4}$ and $150 \mathrm{ml}$ of distilled water by heating and stirring. Cool and dilute to $1000 \mathrm{ml}$ with distilled water.

\section{Procedure}

A. Calibration of System: Turn on all units of the system and pump reagents for at least 30 minutes to allow the system to stabilize. Adjust the puff volume to $35 \mathrm{ml}$ as measured with a soap film manometer.

Place a few small pieces of Teflon or polypropylene in the clean, dry $200 \mathrm{ml}$ syringe, flush the syringe several times with $\mathrm{N}_{2}$ and then, with $200 \mathrm{ml}$ of $\mathrm{N}_{2}$ in the syringe, cap the outlet with a septum stopper. Flush the microsyringe several times with $\mathrm{H}_{2} \mathrm{~S}$ and then inject $20 \mu \mathrm{l}$ of $\mathrm{H}_{2} \mathrm{~S}$ into the $200 \mathrm{ml}$ syringe. Shake the syringe so that the pieces of plastic move to mix the gases. Remove as much air as possible from the plastic bag by applying a slight vacuum, then transfer the gas mixture from the syringe to the bag. Connect the bag to the Cambridge pad holder with a pad in place and take five puffs on the bag. Repeat this entire procedure at least 3 times. Read the net absorbance $\left(A_{n e t}\right)$ for the 3 middle puffs for each of the gas mixture preparations, other than the first preparation which serves to flush out the sampling system, and average the readings. Measure the room temperature ( $T$ ) and barometric pressure $\left(P_{B}\right)$ and calculate the response of the system in terms of $\mu \mathrm{g} \mathrm{H}_{2} S$ per puff per $A_{\text {net }}$ :

$\mu \mathrm{g} \mathrm{H}_{2} \mathrm{~S} / 35 \mathrm{ml} / \mathrm{A}=20 \mu \mathrm{l} \mathrm{H} \mathrm{H}_{2} \mathrm{~S} \cdot \frac{\mathrm{P}_{\mathrm{B}}}{760} \cdot \frac{273}{\mathrm{~T}[\mathrm{~K}]} \cdot \frac{1.539}{\mathrm{~A}_{\text {net }}} \cdot \frac{35}{200}$

The above standard corresponds to about $5 \mu \mathrm{g}$ of $\mathrm{H}_{2} \mathrm{~S}$ per $35 \mathrm{ml}$ puff and is suitable for routine calibration of the 
system. However, when the system is initially set up and occasionally thereafter, additional standards of varying concentration should be run to verify a linear relation between concentration and absorbance over the concentration range of interest.

B. Analysis of Cigarettes Following Calibration: Use a fresh Cambridge pad for each cigarette. Verify that the puff volume is $35 \mathrm{ml}$, adjusting if necessary. Attach the cigarette to the Cambridge pad holder with a latex sleeve. Light the cigarette and smoke to an average butt length of $23 \mathrm{~mm}$ for non-filter or tipping paper $+3 \mathrm{~mm}$ for filter cigarettes. Take a clearing puff by removing the cigarette from the holder just before the puff is taken. Then remove the Cambridge pad assembly and take at least one further puff to establish the baseline. Record the number of smoking puffs.

Calculate the net absorbance for each of the recorded peaks, including the clearing puff. Sum these absorbance values ( $=\Sigma \mathrm{A}_{\text {net }}$ ). Calculate the $\mathrm{H}_{2} \mathrm{~S}$ delivery using this sum and the sensitivity determined in calibration:

$\mu \mathrm{g} \mathrm{H}_{2} \mathrm{~S}$ per cigarette $=\left(\mu \mathrm{g} \mathrm{H}_{2} \mathrm{~S} / 35 \mathrm{ml} / \mathrm{A}\right) \Sigma \mathrm{A}_{\text {net }}$

$\mu \mathrm{g} \mathrm{H}_{2} \mathrm{~S}$ per puff $=\left(\mu \mathrm{g} \mathrm{H}_{2} \mathrm{~S}\right.$ per cigarette $) /$ No. of smoking puffs

\section{RESULTS AND DISCUSSION}

In Figure 3 is shown a reproduction of a typical chart recording obtained in the calibration of the system and the smoking of three randomly selected cigarettes of the same brand, a commercial U.S. $85 \mathrm{~mm}$ with cellulose acetate filter. It can be seen that the peaks for the puffs are well resolved, indicating a satisfactorily low level of sample interaction. The peaks are very sharp which is typical of an AutoAnalyzer system where the sampling time is not long enough to nearly attain steady state condition. The time required to analyze a cigarette is that time required to smoke the cigarette (1 minute per puff) plus 2 minutes for the clearing puff and a blank puff to establish the baseline. The calibration requires typically about 25 minutes. The residence time in the AutoAnalyzer system is about four minutes.

In the initial development work, the efficiency of the absorbing coil was investigated by comparing the response obtained for a standard gas mixture with the present single coil system to that obtained using two 14-turn coils in series for absorption. It was found that there was no significant difference in average response ( $t$-test, 0.05 level) which led to the conclusion that the single coil is extremely efficient and scrubs essentially all of the $\mathrm{H}_{2} \mathrm{~S}$ from the gas stream. This comparison was made using the normal once a minute, 2-second, $35 \mathrm{ml}$ puff and also a continuous $200 \mathrm{ml}$ puff at the same $17.5 \mathrm{ml} / \mathrm{s}$ flow rate. In addition, the use of one vs. two absorption coils was compared for absorption of $\mathrm{H}_{2} \mathrm{~S}$ from gas phase of cigarette smoke by analyzing an $85 \mathrm{~mm}$ commercial U.S. cigarette with cellulose acetate filter repetitively with each system. The average results obtained for four cigarettes using two coils were $30.2 \mu \mathrm{g} \mathrm{H}_{2} \mathrm{~S}$ per cigarette or $3.90 \mu \mathrm{g}$ per puff, not significantly different $(0.05$ level) from those obtained using one coil, which for 15 cigarettes averaged $30.8 \mu \mathrm{g} /$ cigarette or $3.72 \mu \mathrm{g} / \mathrm{puff}$.

Figure 3. Typlcal chart recording obtained in callbration and analysis of clgarettes.

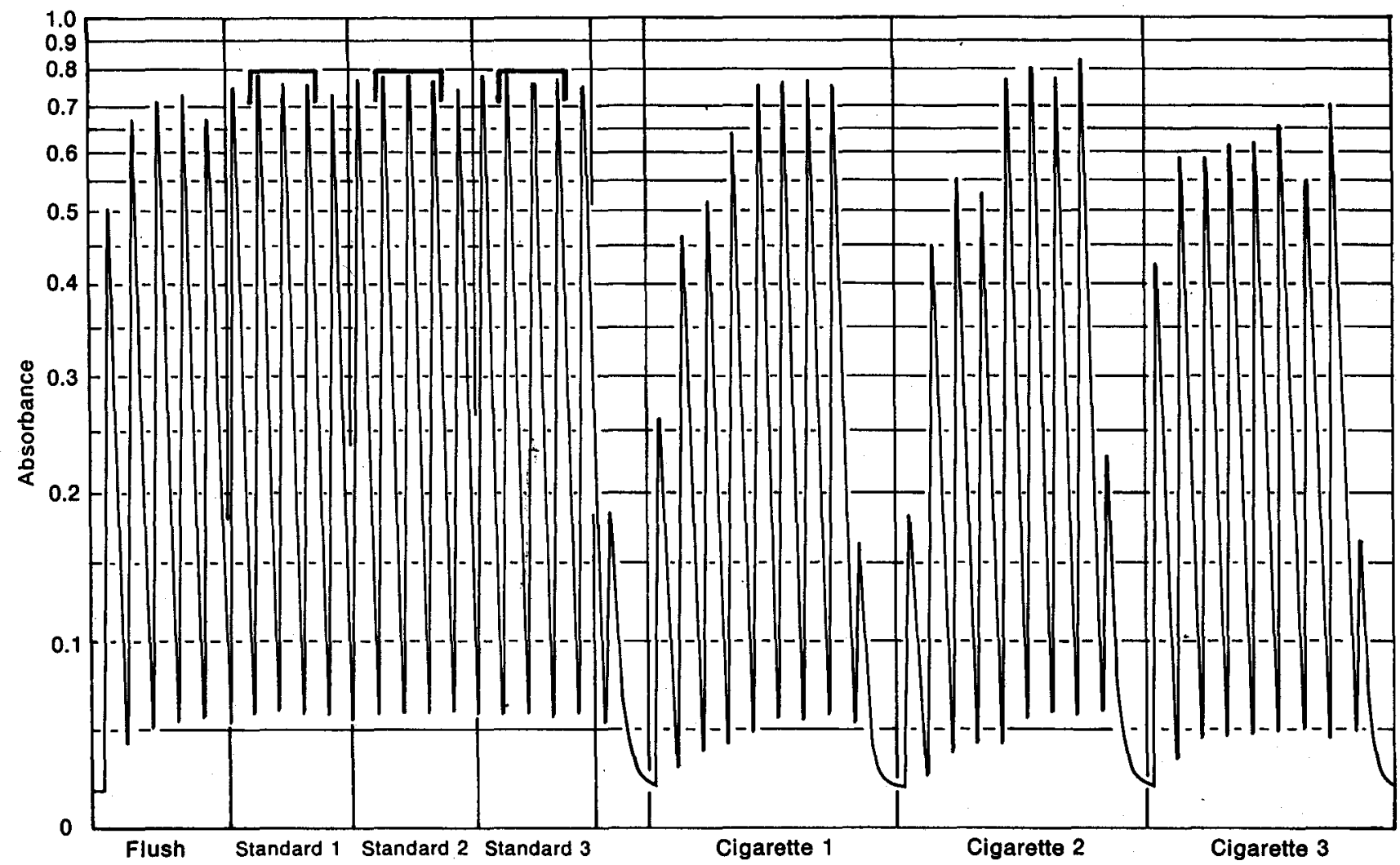


In view of the extreme effect of contact of the gas phase with stainless steel causing losses of $\mathrm{H}_{2} \mathrm{~S}$ exceeding $50 \%$ as observed by Horton and Guerin (2), it was considered desirable to ascertain the effect of the brass critical flow orifice through which the gas phase passes before absorption. This was done by comparing results for $\mathrm{H}_{2} \mathrm{~S}$ in gas phase of a commercial $85 \mathrm{~mm}$ cellulose acetate filter cigarette obtained with the orifice located in the normal position just behind the solenoid valve to results with the orifice placed between the flowmeter and liquid reservoir where it would not affect the $\mathrm{H}_{2} \mathrm{~S}$. With the orifice in the usual position, the average delivery found for 3 cigarettes was $4.06 \mu \mathrm{g} \mathrm{H}_{2} \mathrm{~S} /$ puff compared to an average of 4.00 found with the orifice relocated. Obviously, no deleterious effect is apparent due to the gas phase contacting the orifice before absorption.

The effect of aging of the absorbed gas phase prior to addition of the colorimetric reagents was briefly examined. With the described system, about 30 seconds elapse from the time the absorbate is collected in the C5 debubbler until the stream is mixed with the acidic "amino" reagent. To examine the stability of the absorbate, the system was modified by inclusion of a mixing coil between the point where the absorbate stream is segmented with air bubbles and where the "amino" reagent is added. This change results in the alkaline absorbate being aged for about three times as long as in the normal system and was found to have no significant effect on results for $\mathrm{H}_{2} \mathrm{~S}$ in the gas phase of a commercial U.S. $85 \mathrm{~mm}$ cigarette with cellulose acetate filter. Average results were $30.8 \mu \mathrm{g}$ per cigarette with the normal system (15 cigarettes) compared to $30.7 \mu \mathrm{g}$ per cigarette (3 cigarettes) obtained with the system with extended aging time.

The chemical reaction used to detect hydrogen sulfide involves its reaction with $\mathrm{p}$-aminodimethylaniline and ferric ion to form colored species, predominantly methylene blue. This reaction has been studied in detail by Gustafsson (1) and the conditions recommended by her have, for the most part, been incorporated in this system. However, only 2 minutes are allowed for color development whereas Gustafsson reports that color development is complete after 15 minutes. This difference was found to have no significant effect on the average results for $\mathrm{H}_{2} \mathrm{~S}$ in the gas phase of a U.S. commercial $85 \mathrm{~mm}$ cigarette with cellulose acetate filter, the same brand as used for the comparison of one vs. two absorption coils described above. With the normal procedure, the average for $15 \mathrm{ci}-$ garettes of $30.8 \mu \mathrm{g}$ per cigarette or $3.72 \mu \mathrm{g}$ per puff does not differ significantly $(0.05$ level) from the average for three cigarettes of $29.0 \mu \mathrm{g}$ per cigarette or $3.47 \mu \mathrm{g}$ per puff obtained using a total color development time of $19 \mathrm{~min}$ utes. The additional time was obtained by inserting two $40 \mathrm{ft}$. time delay coils in the AutoAnalyzer flow stream.

As discussed by Gustafsson and also by Johnson and Nishita (3), the relation between concentration of $\mathrm{H}_{2} \mathrm{~S}$ and absorbance is not adequately described by Beer's law, especially at higher concentrations where methylene blue tends to form dimeric ions. The relation was investigated with the present system without dilution using various gas
Figure 4. Relation between absorbance and concentratlon.

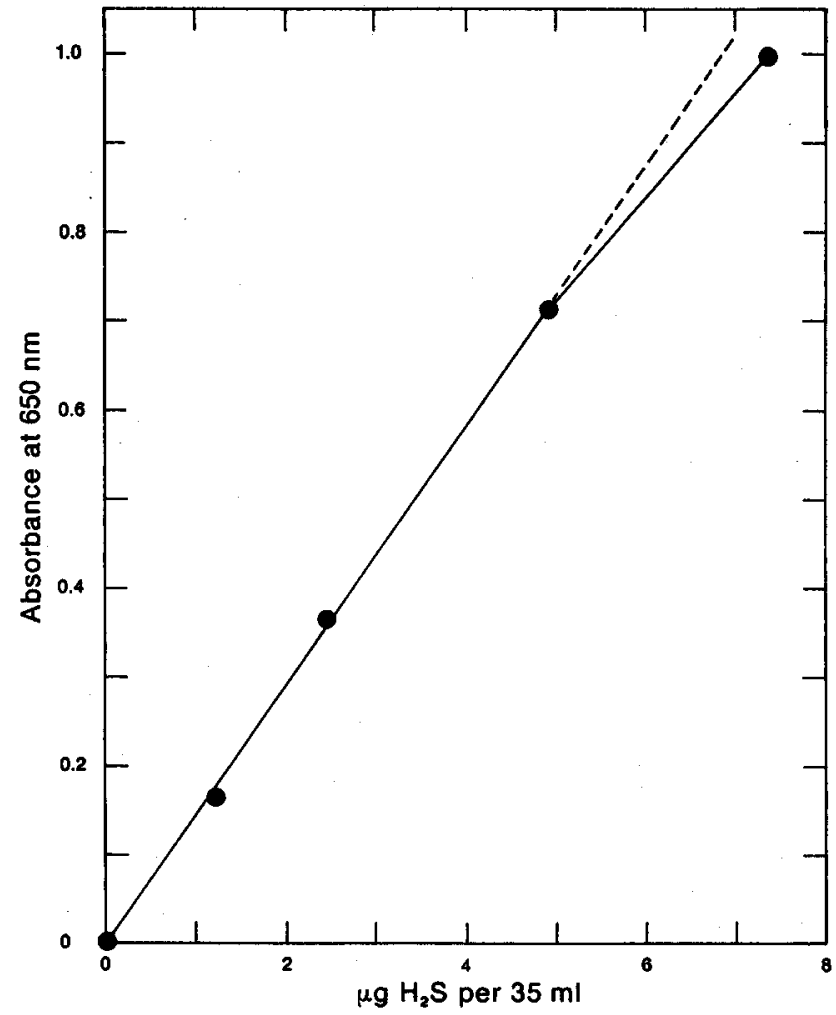

standards and the data are shown graphically in Figure 4. Beer's law is closely followed up to an absorbance of about 0.7 , but above this, the relative response decreases. The practical effect of this in the analysis of cigarettes delivering relatively high levels of $\mathrm{H}_{2} \mathrm{~S}$ is that the delivery is slightly underestimated when only a single point calibration is used as described in the procedure. This error can, of course, be eliminated by using a multi-point calibration. Alternatively, the system may be modified as described above to provide additional dilution of the stream before colorimetry.

Eleven commercial U.S. and University of Kentucky reference cigarettes have been analyzed using this system without the dilution modification and the average results obtained on smoking two or three randomly selected cigarettes of each brand are shown in Table 1. The results exhibit the expected trends in that non-filter and cellulose acetate filter cigarettes deliver the highest level of $\mathrm{H}_{2} \mathrm{~S}$, activated carbon is quite effective in removing $\mathrm{H}_{2} \mathrm{~S}$ and cigarettes with air dilution generally show a reduction in $\mathrm{H}_{2} \mathrm{~S}$ delivery. The standard deviations for a single cigarette for each sample and also pooled over all samples, as shown in Table 1, indicate the precision of the procedure. Relative standard deviations have also been calculated for the eleven samples and the average of these are $10.8 \%$ for $\mu \mathrm{g} \mathrm{H}_{2} \mathrm{~S} /$ cigarette and $8.8 \%$ for $\mu \mathrm{g}_{2} \mathrm{~S} /$ puff. Another estimate of the precision was obtained by analyzing a total of 15 randomly selected cigarettes (commercial U.S. $85 \mathrm{~mm}$ brand with cellulose acetate filter) over a several-day period. The standard deviations were $3.67 \mu \mathrm{g} \mathrm{H}_{2} \mathrm{~S}$ per cigarette and $0.284 \mu \mathrm{g}$ per puff which correspond to relative standard deviations of $11.9 \%$ and $7.6 \%$. A large part of this variability is likely 
Table 1. Dellvery of $\mathrm{H}_{2} \mathrm{~S}$ in gas phase of varlous U.S. cigarettes.

\begin{tabular}{|c|c|c|c|c|c|}
\hline \multirow{2}{*}{$\begin{array}{l}\text { Cigarette type } \\
\text { (all } 85 \mathrm{~mm} \text { ) }\end{array}$} & \multirow{2}{*}{$\begin{array}{l}\text { Number of } \\
\text { cigarettes }\end{array}$} & \multicolumn{2}{|c|}{$\mu g \mathrm{H}_{2} \mathrm{~S} /$ cigarette } & \multicolumn{2}{|c|}{$\mu g \mathrm{H}_{2} \mathrm{~S} /$ puff } \\
\hline & & Average & S.D. & Average & S.D. \\
\hline \multicolumn{6}{|l|}{ Non-filter } \\
\hline $1 R 1^{*}$ & 3 & 46.4 & 5.38 & 4.36 & 0.452 \\
\hline 1R2* & 3 & 38.7 & 6.54 & 3.99 & 0.452 \\
\hline Brand A & 3 & 34.0 & 2.71 & 3.64 & 0.123 \\
\hline \multicolumn{6}{|l|}{ Cellulose acetate filter } \\
\hline 1R2F * & 3 & 39.1 & 3.26 & 4.51 & 0.116 \\
\hline Brand B & 3 & 49.7 & 5.12 & 5.73 & 0.348 \\
\hline Brand $\mathrm{C}$ & 3 & 38.3 & 2.24 & 4.78 & 0.279 \\
\hline Brand D & 3 & 31.2 & 4.83 & 4.06 & 0.351 \\
\hline \multicolumn{6}{|l|}{ Cellulose acetate + carbon filter } \\
\hline Brand $E$ & 2 & 18.5 & 3.06 & 1.97 & 0.467 \\
\hline \multicolumn{6}{|l|}{ Air-diluted filters } \\
\hline Brand F & 3 & 36.2 & 1.49 & 4.53 & 0.188 \\
\hline Brand $\mathbf{G}$ & 3 & 18.1 & 1.22 & 3.02 & 0.205 \\
\hline \multirow[t]{2}{*}{ Brand $\mathrm{H}$} & 2 & 18.8 & 2.72 & 2.70 & 0.389 \\
\hline & \multicolumn{4}{|c|}{$3.952 * *$} & $0.3196^{* *}$ \\
\hline
\end{tabular}

* University of Kentucky research cigarettes.

attributable to the typical variation normally encountered between individual cigarettes of a sample.

These results for $\mathrm{H}_{2} \mathrm{~S}$ in smoke are of the same general magnitude as those reported by other investigators using wet chemical techniques. Morie, using a potentiometric sulfide ion electrode method, reported $42 \mu \mathrm{g} \mathrm{H}_{2} \mathrm{~S} /$ cigarette for a domestic blend with or without a cellulose acetate filter and $19 \mu \mathrm{g} /$ cigarette for a domestic blend with a cellulose acetate - carbon filter (5). Mattina found $34 \mu \mathrm{g} /$ cigarette for a $70 \mathrm{~mm}$ non-filter commercial cigarette using a titrimetric $\left(\mathrm{Ag}^{+}\right)$procedure with potentiometric endpoint detection (4). Terrell and Schmeltz (6) reported $4.5 \mu \mathrm{g} \mathrm{H}_{2} \mathrm{~S}$ in the fifth puff of an $85 \mathrm{~mm}$ commercial cigarette using a colorimetric methylene blue procedure. However, Horton and Guerin (2), using a gas chromatographic method with flame photometric detection, reported results for a variety of cigarettes which were approximately double the results by the wet chemical procedures. They suggest that the wet methods give

Table 2. Results obtalned for recovery of $\mathrm{H}_{2} \mathrm{~S}$ added to gas phase of a $85 \mathrm{~mm}$ cigarette with acetate filter.

\begin{tabular}{l|cc|c}
\hline \multirow{2}{*}{ Run } & \multicolumn{2}{|c|}{$\mathrm{H}_{2} \mathrm{~S}$ found [ $\mu \mathrm{g} /$ cigarette] } & \multirow{2}{*}{$\begin{array}{c}\text { Amount of } \\
\mathrm{H}_{2} \mathrm{~S} \text { added } \\
{[\mu \mathrm{g}]}\end{array}$} \\
\cline { 2 - 3 } & no addition & with addition & \\
\hline 1 & 38.6 & 54.5 & 20.3 \\
2 & 33.1 & 52.7 & 21.0 \\
3 & 33.2 & 62.4 & 20.2 \\
4 & 37.8 & 55.0 & 20.3 \\
\hline Average & 35.68 & 56.15 & 20.45 \\
S.D. & 1.47 & 2.14 & 0.18
\end{tabular}

$\%$ recovery of addition $=\frac{100(56.15-35.68)}{20.45}=100.1 \%$
** Pooled standard deviation for the 11 cigarette samples.

erroneous results due to non-specificity of those analytical techniques or reactions after trapping.

In an effort to resolve this disagreement, recovery tests were carried out using the present procedure with gaseous $\mathrm{H}_{2} \mathrm{~S}$ added to the gas phase of a cigarette with cellulose acetate filter as the gas phase exited the Cambridge pad holder. This was done by inserting a glass tee, with a septum on one leg, in the system between the pad holder and solenoid valve and injecting a total of $15 \mu \mathrm{l}$ of $\mathrm{H}_{2} \mathrm{~S}$ during puffs 2 through 6 , about $3 \mu$ being injected while each of these puffs was being taken. Similar cigarettes were analyzed with no $\mathrm{H}_{2} \mathrm{~S}$ additions and also additions were made while puffing only air through the Cambridge pad to establish the level of $\mathrm{H}_{2} \mathrm{~S}$ added. Because of the higher levels of $\mathrm{H}_{2} \mathrm{~S}$ expected in the addition runs, the AutoAnalyzer manifold included the modification to provide dilution of the stream before colorimetry. Also, a three-point calibration was done, fitting the points with a least squares quadratic equation to eliminate any error due to deviation from Beer's law. These changes were found to not significantly alter the results for $\mathrm{H}_{2} \mathrm{~S}$ for the cigarette being examined. The results of this addition experiment, shown in Table 2, indicate quantitative recovery of the added $\mathrm{H}_{2} \mathrm{~S}$ even though the uncertainty in recovered $\mathrm{H}_{2} \mathrm{~S}$ is rather large (95\% confidence limits are 20.47 $\pm 6.3 \mu \mathrm{g} \mathrm{H}_{2} \mathrm{~S}$ ) due to the variability in individual results. The ability to recover $\mathrm{H}_{2} \mathrm{~S}$ added to the gas phase provides assurance that the present procedure provides relatively accurate results and, by implication, that extreme losses of $\mathrm{H}_{2} \mathrm{~S}$ are not encountered in the previously described wet methods. However, in the present method or in any of those in which a normal Cambridge pad holder is used with the whole puff being analyzed, about one-fourth of the puff ages for one minute because of the volume of the holder. 
Using the value of $69 \%$ decomposition of $\mathrm{H}_{2} \mathrm{~S}$ in the gas phase in the first minute of aging which was reported by Horton and Guerin (2), about $17 \%$ of the total $\mathrm{H}_{2} \mathrm{~S}$ could be lost due to this hold-up volume. Another factor which may be important in explaining the difference between wet methods and the gas chromatographic method is that only a $0.14 \mathrm{ml}$ sample of the puff is used in the gas diromatographic procedure (2) and perhaps this small sample is not adequately representative of the whole puff.

This procedure, like most of the previously published methods, is designed to determine $\mathrm{H}_{2} \mathrm{~S}$ in gas phase. Although $\mathrm{H}_{2} \mathrm{~S}$ is a gas at room temperature (boiling point: $-60^{\circ} \mathrm{C}$ ), this does not necessarily mean that the total $\mathrm{H}_{2} \mathrm{~S}$ delivered in mainstream smoke will be present in the gas phase obtained by use of a Cambridge pad. One of the published procedures, that reported by Mattina (4), uses whole smoke as the sample and, as noted before, his results are in agreement with those by other wet methods. Several experiments to gain information on the partitioning of $\mathrm{H}_{2} \mathrm{~S}$ between the gas and particulate phases have been carried out with the present procedure, and the results suggest that most of the $\mathrm{H}_{2} \mathrm{~S}$ is present in the gas phase. The first was a comparison of the gas phase $\mathrm{H}_{2} \mathrm{~S}$ delivery of an U.S. $85 \mathrm{~mm}$ cigarette with cellulose acetate filter when smoked normally to that when smoked after detaching the filter. In each case, the length of cigarette paper was the same to avoid differences in diffusion of $\mathrm{H}_{2} \mathrm{~S}$ through the paper. Four cigarettes each with and without filter were smoked alternately and the average of those smoked with filter was $28.9 \mu \mathrm{g}$ per cigarette or $3.60 \mu \mathrm{g}$ per puff compared to $27.2 \mu \mathrm{g}$ per cigarette or $3.53 \mu \mathrm{g}$ per puff for those without filter. The differences are not significant $(0.05$ level) indicating that a cellulose acetate filter which removes about a third of the particulate phase does not appreciably alter the level of $\mathrm{H}_{2} \mathrm{~S}$ found in gas phase.

In another experiment, the effect of increasing amounts of particulate material on the Cambridge pad was examined by smoking three cigarettes using the same pad. This was done twice using a commercial U.S. $85 \mathrm{~mm}$ cigarette with cellulose acetate filter and the averages of the two runs in $\mu \mathrm{g} \mathrm{H}_{\mathbf{s}} \mathrm{S}$ per cigarette were: first cigarette, 31.54 ; second cigarette, 31.30; and third cigarette, 28.12. While the trend is suggestive of increasing absorption of $\mathrm{H}_{2} \mathrm{~S}$ as the amount of particulate matter on the pad increases, the differences are not statistically significant ( 0.05 level, analysis of variance) and are rather small even if real.

In an attempt to directly compare the level of $\mathrm{H}_{2} \mathrm{~S}$ in whole smoke to that in gas phase, three cigarettes, $85 \mathrm{~mm}$ with cellulose acetate filter, were smoked without using a Cambridge pad in the holder. The average of the results was $30.8 \mu \mathrm{g} \mathrm{H}_{2} \mathrm{~S}$ per cigarette, exactly the same as the average obtained using a Cambridge pad. It was observed that most of the particulate phase seems to pass through the absorber without being absorbed. Further, any smoke which is absorbed appears not to contribute appreciably to the absorbance measured at $650 \mathrm{~nm}$, as was indicated by running cigarettes with water being introduced in place of the iron (III) reagent which serves to eliminate the response to sulfide. In this experiment, the trapping efficiency of the system for any $\mathrm{H}_{2} \mathrm{~S}$ in the particulate phase is not known and therefore the results do not prove that all of the $\mathrm{H}_{2} \mathrm{~S}$ is in the gas phase. However, the system would be expected to have some efficiency for extracting $\mathrm{H}_{2} \mathrm{~S}$ from particulate phase and thus the equality of results for gas phase and whole smoke suggests that the proportion of $\mathrm{H}_{2} \mathrm{~S}$ in the particulate phase is small.

While the combined smoking and analysis system has only been applied, as yet, to the determination of gas phase $\mathrm{H}_{2} \mathrm{~S}$, it should be generally applicable for other analyses, the principal requirements being an efficient absorbing liquid and an analytical procedure which is adaptable to the AutoAnalyzer. The ability of the system to yield puffby-puff analyses should be of special interest in studies of cigarette combustion and filtration.

\section{SUMMARY}

A system has been developed wherein the gas phase produced on smoking a cigarette through a Cambridge pad is analyzed, on a puff-by-puff basis, for a desired component using automated colorimetry. The system consists of an AutoAnalyzer I and a simple, 1-port smoking machine. The continuous gas stream from the smoking machine, either gas phase or intervening air, is passed concurrently with a stream of absorbing solution through a glass coil. Following passage through the coil, the solution is separated from the gas stream and introduced into the AutoAnalyzer for continuous measurement of the concentration of the absorbed component. The entire system is calibrated using standard gas mixtures puffed in the same manner as the cigarette. The puff profile is essentially rectangular. Chief benefits expected from use of this system include the ability to obtain puff-by-puff measurements, a minimum time for reaction to occur in the gas phase and essentially no sample handling other than smoking the cigarette.

The system has been utilized for the determination of hydrogen sulfide in gas phase using $0.1 \mathrm{~N} \mathrm{NaOH}$ as the absorbing solution and the "methylene blue" colorimetric reaction. Results obtained on a variety of commercial U.S. brands ranged from 18 to $50 \mu \mathrm{g}$ of $\mathrm{H}_{2} \mathrm{~S}$ per cigarette, similar to results reported by other investigators using wet chemical methods. The accuracy of the results is supported by recovery tests wherein gaseous $\mathrm{H}_{2} \mathrm{~S}$ added to the gas phase is completely recovered. The average relative standard deviations obtained with 11 U.S. commercial or reference cigarette samples using random selection of the cigarettes is $10.8 \%$ for $\mu \mathrm{g}$ of $\mathrm{H}_{2} \mathrm{~S}$ per cigarette and $8.8 \%$ for $\mu \mathrm{g}$ of $\mathrm{H}_{2} \mathrm{~S}$ per puff for a single cigarette. The basic system is thought to be applicable to the determination of a number of other components in gas phase.

\section{ZUSAMMENFASSUNG}

Es wurde ein Analysenverfahren entwickelt, mit dem unter Einsatz automatischer Kolorimetrie die Gasphase des Rauches einer iber ein Cambridge-Filter abgerauditen 
Cigarette zugweise auf den Gehalt an einer bestimmten Verbindung untersucht werden kann. Das System besteht aus dem Gerät AutoAnalyzer I und einer einfachen $\mathrm{Ab}$ rauchmaschine mit einem Rauchkopf für eine Cigarette. Das der Raudhmaschine kontinuierlich entströmende Gas - die Gasphase des Rauches oder in den Zugpausen Luft wird zusammen mit einer Absorptionslösung durch eine Glasrohrspirale geleitet. Nach dem Passieren dieser Spirale wird die Lösung vom Gasstrom getrennt und in den AutoAnalyzer zur kontinuierlichen Messung der Konzentration des absorbierten Gasphasenbestandteiles überführt. Die Versuchsanordnung wird mit Standard-Gasgemischen geeicht, die entsprechend dem Verrauchen von Cigaretten zugweise eingesetzt werden. Das Zugprofil ist überwiegend rechteckig. Der Vorteil des Verfahrens liegt vor allem darin, daß Analysen zugweise durchgeführt werden können, daß die Gasphasenbestandteile nur ein Minimum an Zeit zur Reaktion zur Verfügung haben und daß, abgesehen vom Abrauchen der Cigaretten, keine Probenbehandlung nötig ist.

Das Verfahren wurde für die Bestimmung von Schwefelwasserstoff in der Gasphase unter Benutzung von 0,1 N $\mathrm{NaOH}$ als Absorptionslösung angewendet, wobei die kolorimetrische Reaktion auf der Bildung von "Methylenblau" basierte. Bei einer Reihe von verschiedenen handelsublichen amerikanischen Cigarettenmarken beliefen sich die Werte auf 18 bis $50 \mu \mathrm{g} \mathrm{H}_{2} \mathrm{~S}$ je Cigarette und entsprachen damit Befunden, die von anderen Forschern mit naßs-chemischen Methoden erhalten wurden. Die Genauigkeit der Ergebnisse wurde in Rüdkgewinnungsversuchen bestätigt, bei denen der der Gasphase zugesetzte gasförmige Schwefelwasserstoff vollständig wiedergefunden wurde. Bei elf Zufallsstichproben von amerikanischen Cigarettenmarken oder Referenzcigaretten betrug der Variationskoeffizient im Durchschnitt 10,8\%, bezogen auf die Werte je Cigarette, und $8,8 \%$, bezogen auf die Werte je Zug einer einzelnen Cigarette. Es ist anzunehmen, daß sich das Verfahren im Prinzip auch für die Bestimmung einiger anderer Inhaltsstoffe der Gasphase eignet.

\section{RESUME}

Un système a été mis au point par lequel la phase gazeuse obtenue en fumant une cigarette à travers un filtre Cambridge est analysé, bouffée par bouffée, sur un composant donné, en utilisant la colorimétrie automatique. Le système comporte un AutoAnalyzer $I$ et une machine à fumer simple a 1 canal. Le flux continu de gaz de la machine a fumer - phase gazeuse ou air intermédiaire - est passé par une spirale de verre en même temps qu'un courant de solution absorbante. Apres le passage dans la spirale, la solution est séparée du flux de gaz et introduite dans l'AutoAnalyzer pour la mesure continue de la concentration du composant absorbé. Tout le système est étalonné par des mélanges de gaz standard aspirés par bouffées, de la même manière que la fumée des cigarettes. Le profil des bouffées est essentiellement rectangulaire. Les avantages majeurs de ce système sont la possibilité d'obtenir des mesures bouffée par bouffée, un temps minimum évitant des réactions dans la phase gazeuse et pratiquement aucune manipulation d'echantillons autre que le fumage proprement dit.

Le système a été utilisé pour la détermination de l'acide sulfhydrique dans la phase gazeuse en utilisant du $\mathrm{NaOH}$ $0,1 \mathrm{~N}$ comme solution absorbante et la réaction au «bleu de méthylène» pour la colorimétrie. Les résultats obtenus sur une variété de marques commerciales des Etats-Unis varient entre 18 et $50 \mu \mathrm{g} \mathrm{de} \mathrm{H}_{2} \mathrm{~S}$ par cigarette, résultats correspondant à ceux obtenus par d'autres chercheurs utilisant des méthodes chimiques par voie humide. L'exactitude des résultats est confirmée par des surcharges de $\mathrm{H}_{2} \mathrm{~S}$ gazeux à la phase gazeuse, retrouvées dans leur totalité. Les coefficients de variation moyens obtenus avec des échantillons de sélection aléatoire de 11 cigarettes commerciales et standard des Etats-Unis est de 10,8\% par cigarette et de 8,8\% par bouffée sur une seule cigarette. Le principe de ce système est censé être applicable à la détermination d'autres composants de la phase gazeuse.

\section{REFERENCES}

1. Gustafsson, L.: Determination of ultramicro amounts of sulphate as methylene blue, $I$. The colour reaction; Talanta 4 (1960) 227-235.

2. Horton, A. D., and M. R. Guerin: Quantitative determination of sulfur compounds in the gas phase of cigarette smoke; J. Chromatography 90 (1974) 63-70.

3. Johnson, C. M., and H. Nishita: Microestimation of sulfur in plant materials, soils, and irrigation waters; Anal. Chem. 24 (1952) 736-7.42.

4. Mattina, C. F., Jr.: A potentiometric method for the determination of hydrogen cyanide and hydrogen sulfide in cigarette smoke; Tobacco Sci. 16 (1972) 113114.

5. Morie, G. P.: Determination of hydrogen sulfide in cigarette smoke with a sulfide ion electrode; Tobacco Sci. 15 (1971) 107.

6. Terrell, J. H., and I. Schmeltz: Alternation of cigarette smoke composition, I. Influence of certain additives; Tobacco Sci. 14 (1970) 78-81.

7. Yunghans, R. S., and W.A. Munroe: Continuous monitoring of ambient atmospheres with the Tednicon AutoAnalyzer, In: Technicon Symposia 1965: Automation in analytical chemistry (Proceedings); Mediad Inc., New York, 1966, 279-284.

Addresses of authors:

J.F. Williams,

Liggett \& Myers Tobacco Company, Inc.,

Research Department,

West Main \& Fuller Streets,

Durbam, N.C., 27702, U.S.A.

P. F. Collins,

3202-9 Stonesthrow Lane,

Durbam, N.C., 27713, U.S.A. 